\title{
REIGNY, Actes diplomatiques du XIIe siècle
}

Les actes de l'abbaye cistercienne de Reigny au XII ${ }^{\mathrm{e}}$ siècle. Etat des lieux en vue d'une édition en ligne

\section{Marlène Hélias-Baron}

\section{(2) OpenEdition}

\section{Journals}

Édition électronique

URL : https://journals.openedition.org/cem/5652

DOI : $10.4000 /$ cem.5652

ISSN : 1954-3093

Éditeur

Centre d'études médiévales Saint-Germain d'Auxerre

\section{Référence électronique}

Marlène Hélias-Baron, «REIGNY, Actes diplomatiques du XIle siècle », Bulletin du centre d'études médiévales d'Auxerre / BUCEMA [En ligne], Collection CBMA, mis en ligne le 03 juillet 2008, consulté le 24 septembre 2022. URL : http://journals.openedition.org/cem/5652 ; DOI : https://doi.org/10.4000/ cem.5652

Ce document a été généré automatiquement le 24 septembre 2022.

\section{c) (†) (2)}

Creative Commons - Attribution - Pas d'Utilisation Commerciale - Partage dans les Mêmes Conditions 4.0 International - CC BY-NC-SA 4.0

https://creativecommons.org/licenses/by-nc-sa/4.0/ 


\section{REIGNY, Actes diplomatiques du XIIe siècle}

Les actes de l'abbaye cistercienne de Reigny au XII ${ }^{\mathrm{e}}$ siècle. Etat des lieux en vue d'une édition en ligne

\section{Marlène Hélias-Baron}

1 Tout a commencé en 1104 quand deux ermites, Guérin et Gérard, ont obtenu d'Anséric chevalier d'Avallon et de Guy de Noyers la terre de Saint-Pierre située à proximité de Joux-la-Ville, dans le diocèse d'Autun ${ }^{1}$. Leur aura de sainteté attira des disciples et leur communauté, installée en un lieu fort humide, justement appelé Fons humidus, Fontemoy, se transforma progressivement en un petit monastère ${ }^{2}$. A la mort du deuxième abbé, Julien, au cours de l'année 1128, comme de nombreuses autres communautés encore informelles, le groupe de Fontemoy s'affilia à l'ordre de Cîteaux ${ }^{3}$, devenant alors la cinquième fille de Clairvaux ${ }^{4}$.

En 1134, sous la direction du nouvel abbé, Etienne de Toucy, dépêché par Bernard de Clairvaux, le monastère est déplacé en un lieu plus convenable pour des cisterciens, à Reigny sur les bords de la Cure, à proximité de Vermenton ${ }^{5}$. Changement de lieu, changement d'obédience. Reigny se trouve dans le diocèse d'Auxerre. A partir de là, même si elle n'a jamais essaimé, l'abbaye devint florissante, ce dont témoigne l'accumulation d'actes médiévaux, conservés dans leur majorité aux archives départementales de l'Yonne ${ }^{6}$. Des bribes du chartrier sont également signalées aux archives nationales ${ }^{7}$; la bibliothèque nationale possède pour sa part le cartulaire rédigé à la fin du XIV ${ }^{e}$ ou au début du XV ${ }^{\mathrm{e}}$ siècle ${ }^{8}$.

Ce sont ces documents diplomatiques (originaux et copies confondus) qui m'intéressent, du moins ceux délivrés entre 1104 et 1200 . Actuellement, mon corpus se compose de plus de 130 actes datés de cette période. Ce chartrier de taille moyenne a l'avantage de permettre une étude diplomatique rapide pour appréhender d'un seul coup d'œil - ou presque! - les habitudes documentaires des moines blancs. L'effort portera d'abord sur une étude de la tradition pour comprendre comment les cisterciens considéraient et traitaient leurs archives ; puis sur un examen détaillé des actes en euxmêmes, et enfin sur une analyse de leur contenu. 
La tradition des actes de Reigny ou le bon état de conservation des archives

4 A partir de 129 actes actuellement dépouillés (auxquels il convient d'ajouter neuf notices copiées sur une pancarte), l'objectif est de déterminer avec précision sous quelle forme les documents de Reigny sont disponibles. Combien d'originaux et de copies? Quels sont les types de copies? Datent-elles de l'époque médiévale ou ont-elles été faites par des érudits des époques moderne et contemporaine? Dans quel état le chartrier nous est-il parvenu ? Les moines étaient-ils soucieux de leurs archives?

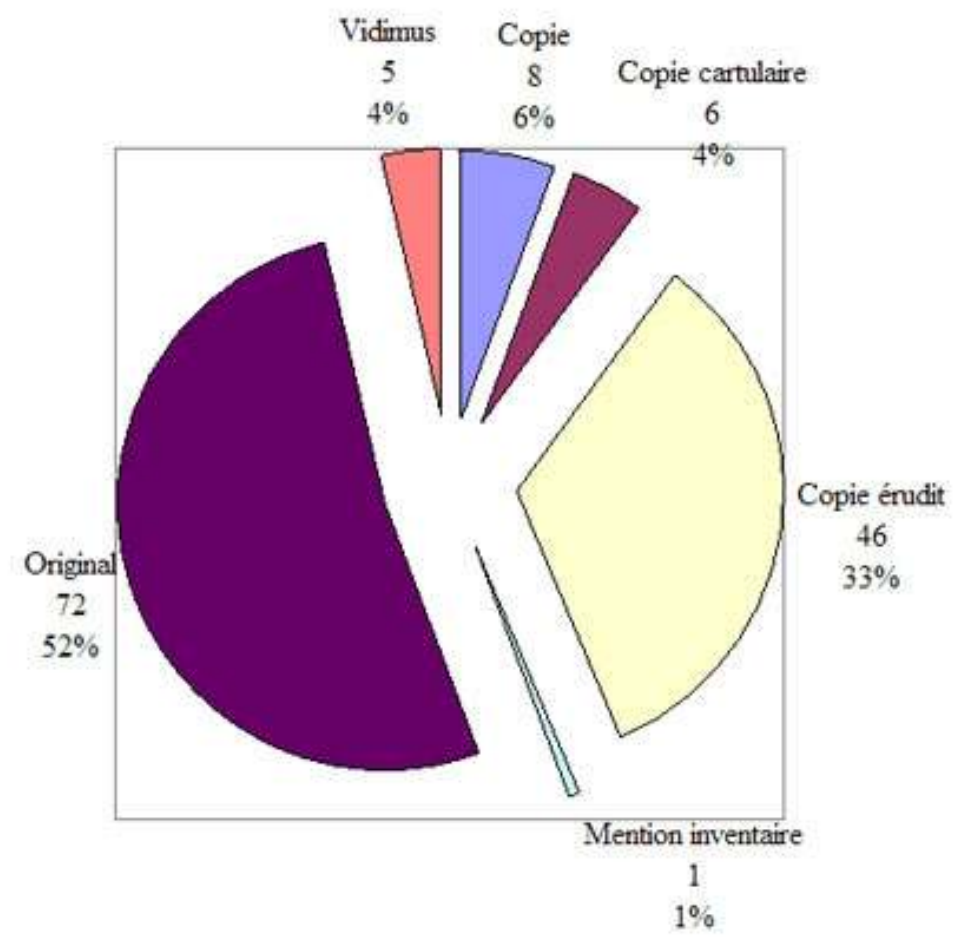

Tableau 1 : Tradition des actes de Reigny

Le soin des originaux

5 Sur 138 documents, 72 sont conservés sous leur forme originale, soit $52 \%$ de l'ensemble. Le pourcentage d'originaux est comparable à celui que j'avais observé non seulement dans le fonds de Clairvaux, abbaye-mère de Reigny (55\% d'originaux), mais aussi de ceux des trois autres premières fondations de Cîteaux ${ }^{9}$.

Les cisterciens prennent un soin presque méticuleux de leurs archives ${ }^{10}$. Ils sont témoins et acteurs de la révolution de l'écrit documentaire qui s'observe à cette époque. Ils veulent que les actions juridiques faites en leur faveur soient rédigées pour lutter contre l'oubli et la malveillance comme l'indiquent les préambules ${ }^{11}$. Ce n'est pas tout : ils veulent que leurs écrits soient notifiés, confirmés et scellés par une autorité, afin d'assurer la défense de leur patrimoine face aux revendications éventuelles ${ }^{12}$.

7 Pour protéger leurs possessions et garantir leurs droits, les moines de Reigny sont prudents et consciencieux.

Des copies authentiques

8 Quand les originaux ne suffisent plus et/ou qu'il est nécessaire d'en avoir des copies authentiques, les moines les ont faits vidimer par diverses autorités: évêque ou officialité d'Auxerre, évêque de Paris, duc de Bourgogne et prévôté de Bétry et Vermenton ${ }^{13}$. Ce fonds contient en effet, à côté des originaux, onze vidimus et une copie 
de vidimus ${ }^{14}$. Chaque fois qu'il est possible de comparer avec l'original, la copie vidimée est fiable, voire exacte au mot près. Pour la rédaction de ces documents, deux moments forts se détachent : le premier au cours du XIII siècle et le second au XV siècle. Dans le premier cas, vu les actions juridiques contenues dans les actes (donations de terres ou exemptions de taxes), il s'agissait probablement de contrer les revendications de plus en plus pressentes de la part d'héritiers ou d'agents royaux et comtaux. Dans le second, c'est le moment où le temporel et le chartrier de l'abbaye ont été réorganisés, après les souffrances occasionnées par le passage de brigands "anglais" dans les années 1350-1360. Dans ces conditions, il est intéressant de mentionner que deux confirmations générales des possessions de l'abbaye faites par Alexandre III en 1164 et Innocent III en 1199 ont été vidimées en 1450 et 1413.

9 Cinq actes sont uniquement disponibles sous cette forme particulière. Trois de ces copies datent du XIII ${ }^{e}$ siècle $^{15}$. Les deux derniers ont été mis au point après 1450 . Ils émanent du « garde du scel » de la prévôté de Bétry et Vermenton ${ }^{16}$.

Copies sur cartulaires et copies d'érudits

10 Six documents sont connus par leur transcription sur trois cartulaires différents.

11 Quatre ont été consignés sur le cartulaire de Reigny ${ }^{17}$. Comme les cinquante autres titres qui y sont consignés, ils concernent la grange abbatiale et les droits pesant sur la Cure ou les environs. La fiabilité des transcriptions est difficile à estimer devant le mauvais état général du recueil. Les deux copies suivantes se trouvent sur d'autres cartulaires monastiques. Une charte a été transcrite sur le premier cartulaire de Pontigny ${ }^{18}$; la deuxième sur celui de Saint-Germain d'Auxerre ${ }^{19}$. Aucune des deux n'apparaît dans le cartulaire de Reigny et aucune n'a été conservée dans le fonds de l'abbaye. S'agissait-il de chirographes dont les parties destinées à Reigny auraient été perdues? C'est possible... En effet, pour le premier acte qui consigne un accord passé vers 1145-1151 entre Pontigny et Reigny au sujet de droits de pâturage autour de Villiers-la-Grange, une charte revenant en 1209 sur le conflit du milieu du XII ${ }^{e}$ siècle, nous apprend qu'il s'agissait d'un chirographe ${ }^{20}$.

Enfin, la teneur de quarante-six actes est connue par les travaux d'ecclésiastiques ou d'érudits, souvent les deux en même temps, des XVII ${ }^{e}$ et XIX ${ }^{e}$ siècles.

$\mathrm{Au}$ cours du XVII siècle, trente-neuf titres datés des années 1120-1500 ont été copiés sur des feuilles de papier, pourvues en plus du contenu de l'acte de courtes analyses en latin ${ }^{21}$. La transcription n'est jamais complète. Le copiste a en effet souvent résumé le dispositif et passé sous silence tout ce qui lui semblait superflu ${ }^{22}$. L'auteur de ce travail était probablement un moine de Reigny, resté anonyme. 


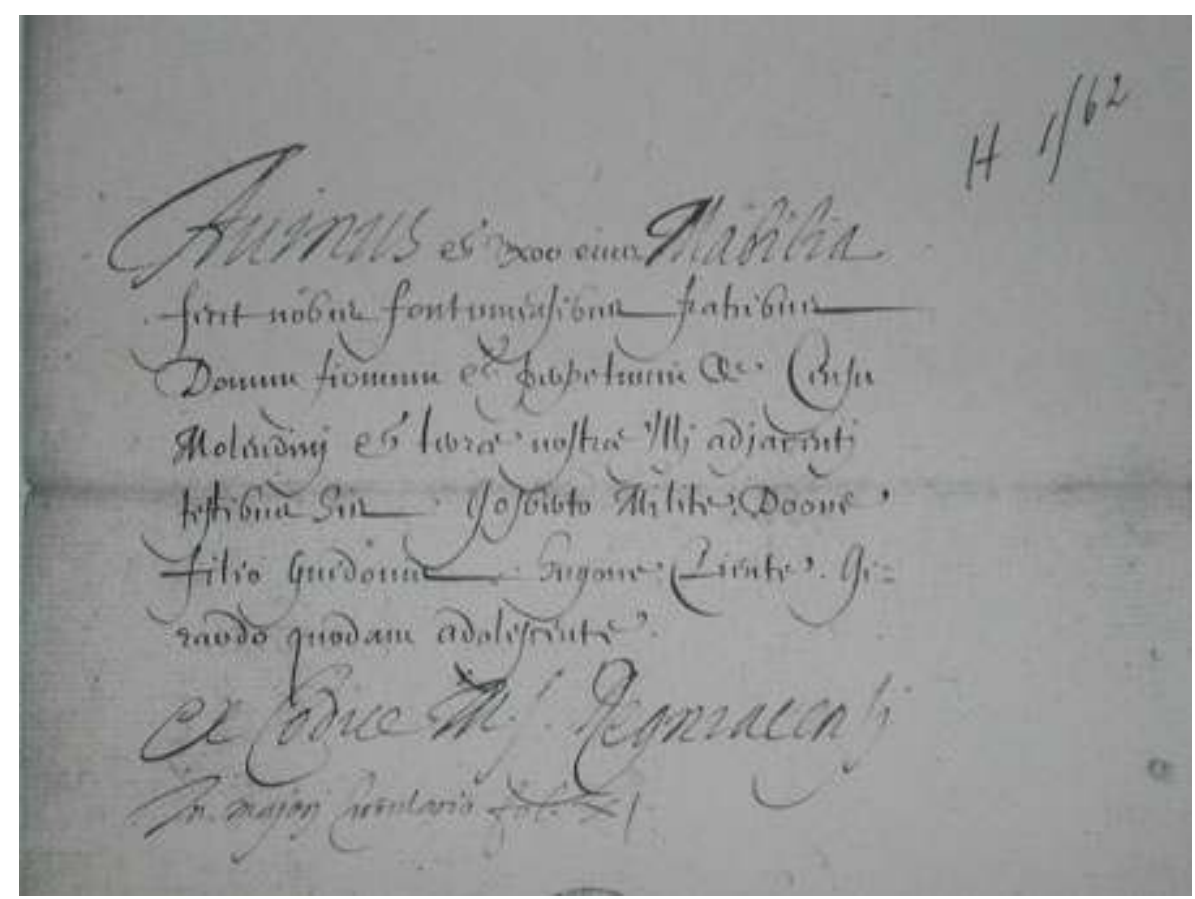

Illustration 1 : Ecriture d'un acte copié au XVIIe siècle. AD Yonne, H 1562-2 recto. (Cliché AD Yonne, extrait).

Les raisons de ce travail n'ont pas été avancées, mais à la même époque, vingt-et-une fiches biographiques de divers abbés de Reigny depuis les origines ont été dressées par Louis-Noël Damy, chanoine d'Auxerre, infatigable transcripteur ${ }^{23}$. Ce ne sont pas à proprement parler des gesta abbatum mais de courtes notes probablement mises au point dans le but de servir de "pense-bête ». Elles ont toutes le même aspect : sur une feuille de papier fin plié en deux, elles consignent le nom de l'abbé, son origine et sa famille, sa fonction dans le monastère (abbé régulier ou commendataire), ses autres charges et une brève biographie.

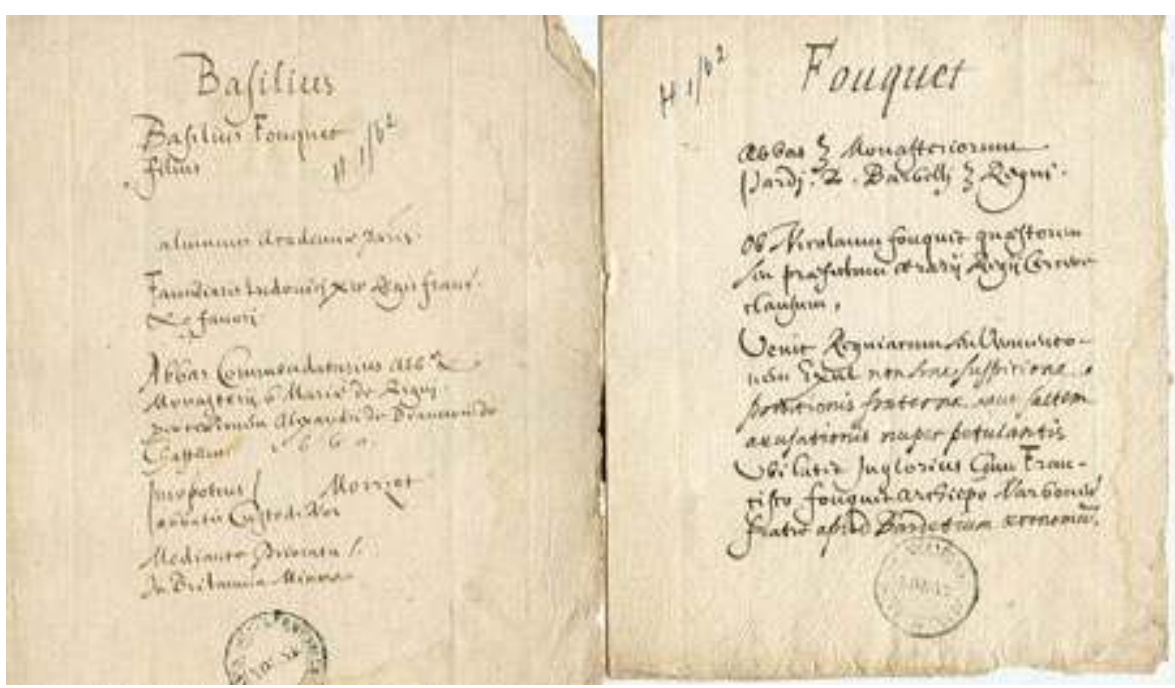

Illustration 2 : Fiche de Basile Fouquet, frère de Nicolas Fouquet, rédigée par Louis-Noël Damy au XVIIe siècle (Cliché AD Yonne).

Même si Louis-Noël Damy n'est pas un moine de Reigny, la transcription des actes et la rédaction des fiches sont peut-être liées. Il pourrait s'agir d'un travail mémoriel sur les origines et l'histoire du monastère voulu par les religieux eux-mêmes, au moment où le 
système de la commende est bien implanté et menace le bon fonctionnement de la communauté.

16 A la fin du XIX siècle, le comte de Chastellux a fait un travail considérable. Il a transcrit le répertoire fait en $1753^{24}$; dans le même temps, il a copié vingt-six documents isolés datés des années 1119-1523. Outre cela, il a repris le cartulaire de Reigny, à l'exception bien entendu des actes rendus illisibles par l'humidité. Son travail est celui d'un érudit, célébré par la Société des sciences historiques et naturelles de l'Yonne en $1912^{25}$. C'est aussi l'ouvrage d'un homme sur les traces de ses ancêtres : les seigneurs de Chastellux ont en effet été parmi les meilleurs bienfaiteurs de Reigny.

Enfin, huit actes ne sont connus que par des copies élaborées au cours du XVI ${ }^{\mathrm{e}}$ siècle, sans aucune marque de validation et un dernier document n'est évoqué que par sa citation dans un inventaire mis au point au tournant des XVII ${ }^{e}$ et XVIII ${ }^{e}$ siècle ${ }^{26}$.

Les actes ont été relativement bien conservés par les moines de Reigny. Grâce au cartulaire, aux inventaires, aux copies d'érudits, le contenu du chartrier médiéval peut être cerné sans trop de difficultés. Des sondages dans les fonds d'abbayes en contact avec Reigny devraient néanmoins permettre de repérer quelques documents absents du fonds étudiér7.

Les actes de Reigny dans tous leurs états : dénombrement et examen diplomatique De la pénurie en actes à une relative abondance

\begin{tabular}{|c|c|}
\hline avant 1120 & 4 \\
\hline $1121-1130$ & 3 \\
\hline $1131-1140$ & 0 \\
\hline $1141-1150$ & 12 \\
\hline $1151-1160$ & 6 \\
\hline $1161-1170$ & 23 \\
\hline $1171-1180$ & 13 \\
\hline $1181-1190$ & 9 \\
\hline $1191-1200$ & 14 \\
\hline Sans date & 54 \\
\hline Total & 138 \\
\hline
\end{tabular}

Tableau 2: Evolution du nombre d'actes au cours du XIIe siècle ${ }^{28}$

Entre 1104 et 1200 , le nombre d'actes n'est pas resté stable, mais a connu des fluctuations liées à la vie du monastère et à la conjoncture « cistercienne ». 
20 Avant 1140, s'observe une pénurie d'actes; cette première période, longue d'une quarantaine d'années, correspond à la communauté originelle, c'est-à-dire à l'ermitage et au monastère installés à Fontemoy. Le jeune établissement attire peu les donations et ses occupants ne pensent pas à rédiger systématiquement les actions juridiques. Treize actes peuvent être datés de cette période. Encore faut-il nuancer ce chiffre, puisque six de ces premiers documents sont des confirmations faites par Etienne II, évêque d'Autun entre 1171 et 1189 .

21 Pendant les trente années suivantes, se manifeste une augmentation irrégulière du nombre d'actes. Elle correspond à l'implantation des cisterciens sur les bords de la Cure et à l'action énergique de leur premier abbé, Etienne de Toucy (1134-1162). Il a sollicité les aumônes des petits seigneurs des environs et les a faites confirmer par les évêques d'Autun ou d'Auxerre, en particulier Hugues de Mâcon ancien abbé de Pontigny et surtout son neveu Alain ancien abbé de Larivour, bref deux « ex-cisterciens ", très enclins à écouter les sollicitations de leurs condisciples.

Une autre raison peut être avancée pour expliquer cette croissance documentaire : le changement de génération au sein de la communauté. Les ermites des origines sont remplacés par des cisterciens qui n'ont pas la mémoire des origines et qui ont un rapport plus fusionnel à l'écrit.

Enfin, les trente dernières années $d u X X^{e}$ siècle correspondent à un certain ralentissement des acquisitions... après l'ère des acquisitions, Reigny entre dans une période de gestion de son patrimoine (qu'il faut nuancer, puisque l'abbaye continue à arrondir son temporel au cours du XIII ${ }^{\mathrm{e}}$ siècle).

Vers 1200 , le chartrier de l'abbaye est relativement bien fourni (autour de 130 actes) : les acquisitions ont permis aux moines de former quelques granges solidement dotées. Le chartrier reflète finalement l'état enviable du temporel monastique.

Petite typologie des actes de Reigny

\begin{tabular}{|l|l|}
\hline Charte & 89 \\
\hline \hline Chirographe & 7 \\
\hline \hline Diplôme royal & 1 \\
\hline \hline Mandement royal & 1 \\
\hline \hline Notice & 29 \\
\hline \hline Pancarte & 1 \\
\hline \hline Privilège pontifical & 10 \\
\hline \hline Total & 138 \\
\hline
\end{tabular}

Tableau 3 : La typologie des actes de Reigny : chartes, notices, chirographes...

La majorité des documents conservés dans les archives de Reigny sont des chartes, ce qui n'est guère surprenant et se retrouve dans les autres fonds cisterciens. Elles ont été 
scellées, placées sous le nom d'une autorité, généralement l'évêque d'Auxerre et dans une moindre mesure celui d'Autun. Rarement pourvues de préambule, elles contiennent dans leur grande majorité une liste de témoins et une clause de corroboration. Elles ont souvent un aspect soigné (écriture régulière, justification à droite et à gauche, voire lettre initiale ornée). En bref, ce sont des documents en bonne et due forme.

Les vingt-neuf notices ensuite. Ce sont des documents de portée plus limitée rédigés à la forme indirecte. Dans le fonds de Reigny, cohabitent deux types de notices:

- soit se sont des actes rédigés par les moines de Fontemoy puis de Reigny eux-mêmes, dont les originaux sont conservés ;

- soit ce sont des copies fabriquées au XVII ${ }^{e}$ siècle ${ }^{29}$. Devant ce travail, il est difficile de savoir si le copiste a transcrit fidèlement ses modèles ou s'il a résumé de manière drastique les chartes qu'il avait sous les yeux. La principale difficulté réside dans le fait que trop peu d'originaux ont été conservés pour servir d'éléments de comparaison.

Parmi ces notices, se trouve un acte suspecté d'être une pancarte. Il n'est connu que par sa transcription du XVII ${ }^{e}$ siècle ${ }^{30}$. Il consigne neuf actions juridiques différentes rédigées sous forme de courtes notices concernant une même terre. Aucune titulature, aucune formule de corroboration ne subsiste (si jamais il y en a eu un jour). Le document ressemble davantage à une notitia traditionum qu'à une véritable pancarte. Le copiste a peut-être rassemblé des donations rédigées sous forme de notices séparées, même si les articulations laissent supposer le contraire.

Enfin, le fonds de Reigny compte six parties de chirographes, dont deux relatent la même affaire ${ }^{31}$. Tous consignent des accords ou des échanges faits avec d'autres établissements monastiques de la région: Saint-Germain d'Auxerre, Saint-Pierre d'Auxerre, Bouras, Vézelay et Crisenon. Ce sont des actes établis dans la seconde moitié du XII ${ }^{\mathrm{e}}$ siècle, à partir de 1169.

Deux exemplaires datés de 1172 pourraient ne former qu'un chirographe ${ }^{32}$. Leur contenu raconte la même histoire, à savoir que les abbés de Pontigny et de Clairvaux à la demande du chapitre général de Cîteaux sont intervenus pour mettre fin à un conflit opposant les moines de Reigny à ceux de Bouras au sujet de la grange nouvelle de VilleSèche et des pâturages de Vavrette - Vaureta (Sougères-en-Puisaye). En fait, dans cette affaire, interviennent les abbés-pères des deux abbayes en conflit. En effet, Bouras est fondé en 1119 par Pontigny et Reigny est fille de Clairvaux. La grange de Ville-Sèche récemment fondée par Reigny empiète sur les terres de Bouras.

Malgré une écriture et des textes identiques ${ }^{33}$, une difficulté rédhibitoire se manifeste, qui empêche d'affirmer qu'il s'agit d'un chirographe complet: la devise (cyrographum), une fois rapprochée, ne coïncide pas.

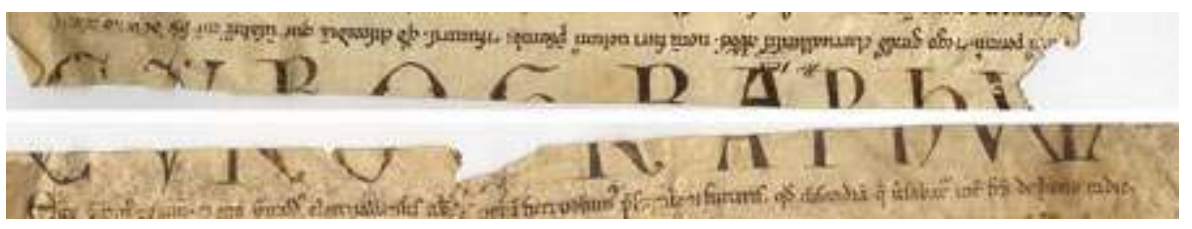

Illustration 3 : Rapprochement par la devise des deux parties de chirographes de 1172 (AD Yonne, H 1627)

31 Comme la partie supérieure a été rongée par l'humidité au point que les marges de gauche et de droite ont des mots illisibles ou coupés, il est néanmoins possible que le 
parchemin se soit rétracté et empêche ainsi le rapprochement exact des deux bords supérieurs.

Des moines en quête d'autorité : les auteurs des actes de Reigny

Les bénéficiaires, plus rarement les disposants, sont allés trouver les autorités les mieux reconnues pour leur demander de notifier ou confirmer les actions juridiques et d'apposer leur sceau sur les actes ${ }^{34}$.

\begin{tabular}{|l|l|}
\hline Papes & 10 \\
\hline \hline Evêques & 58 \\
\hline \hline Abbés & 12 \\
\hline \hline Ecclésiastiques divers & 3 \\
\hline \hline Rois & 2 \\
\hline \hline Ducs/comtes/comtesses & 10 \\
\hline \hline Seigneurs & 17 \\
\hline \hline Total & 112 \\
\hline
\end{tabular}

Tableau 4 : Les auteurs des actes dans le fonds de Reigny.

A tout seigneur, tout honneur: ouvrons cette étude des auteurs d'actes sur les actes pontificaux...

Le premier pape qui délivra un acte à Reigny est Innocent II en janvier $1142^{35}$. Ce n'est guère surprenant quand on connaît l'engagement des cisterciens (et en particulier de Bernard de Clairvaux) en sa faveur pendant le schisme d'Anaclet ${ }{ }^{36}$. Le document en question est une lettre adressée à Gérard, abbé de Molesme, l'enjoignant de respecter le jugement rendu en faveur de Reigny par Hugues de Mâcon, évêque d'Auxerre, Godefroy de la Roche Vanneau, évêque de Langres, et Bernard abbé de Clairvaux. L'abbé de Molesme a dû trouver les arbitres quelque peu partiaux, puisqu'il a sans doute refusé d'appliquer cet ordre. En effet, l'affaire rebondit en 1145 : le pape Lucius II demande alors aux mêmes arbitres d'intervenir pour mettre fin au conflit ${ }^{37}$. On ne sait comment l'affaire se termina puisqu'aucune autre mention de ce litige n'apparait dans les actes de Reigny et qu'aucun original n'en a été conservé.

Dans la seconde moitié du XII ${ }^{e}$ siècle, trois confirmations générales des biens ont été demandées à la curie romaine par les moines. Le 23 août 1147, Eugène III délivra la première d'entre elles. Ce pape étant un ancien cistercien, de surcroît disciple de Bernard de Clairvaux ${ }^{38}$, il n'est guère surprenant que les moines l'aient sollicité pour placer sous sa protection leurs biens. Grâce à cette première confirmation, on peut estimer l'étendue du patrimoine de Reigny au milieu du XII ${ }^{e}$ siècle et voir qu'il n'est pas encore structuré en granges ${ }^{39}$. La deuxième a été délivrée par Alexandre III en 1164 ; la longue énumération des biens prouve que le temporel était alors structuré en huit granges : celle de l'abbaye, Fontemoy (l'ermitage des origines est alors réduit à l'état 
d'exploitation agricole), Oudun, Essert, La Charbonnière, Lichères, Chaux et Beauvoir, à côté desquelles se trouvaient de nombreuses terres non encore rattachées à un domain $\mathrm{e}^{40}$. La troisième a été donnée par Innocent III en $1199^{41}$. Ces privilèges, avec leurs enumerationes bonorum, sont les témoins de l'accroissement progressif du temporel de Reigny au cours du XII ${ }^{e}$ siècle, mais aussi des relations solides entretenues par les cisterciens avec la papauté qui renforce alors son pouvoir en s'appuyant sur les nouveaux mouvements monastiques.

Témoignage de ces liens tissés entre Reigny et la papauté, le dernier document pontifical du XII siècle est une lettre d'Innocent III datée du 23 avril 1200, par laquelle le pape ordonne aux archevêques, évêques et autres ecclésiastiques d'excommunier tous ceux qui s'en prennent de manière violente non seulement aux moines et convers de Reigny, mais aussi à leurs biens, sans que l'on sache exactement quelles violences sont évoquées ${ }^{42}$. Les archives de l'abbaye ne conservent en effet aucun acte faisant mention d'attaques contre ses possessions à cette époque, mis à part les habituelles contestations de terres. Cet acte pontifical est un véritable privilège puisqu'il garantit aux moines une protection spirituelle préalable à tout conflit. Toute réclamation est ainsi considérée comme illégitime, avant tout jugement.

Parmi tous les auteurs d'actes, les moines ont davantage sollicité les évêques. Quelles peuvent en être les raisons?

\begin{tabular}{|l|l|}
\hline Evêques d'Autun & 24 \\
\hline \hline Evêques d'Auxerre & 29 \\
\hline \hline Evêque de Langres & 1 \\
\hline \hline Autres évêques & 2 \\
\hline \hline Total & 58 \\
\hline
\end{tabular}

Tableau 5 : Les évêques, autorités les plus sollicitées.

Les évêques d'Autun et d'Auxerre sont les mieux représentés, puisqu'ils sont auteurs (seuls ou associés à d'autres prélats, évêques de Troyes ou de Langres, et abbés cisterciens) respectivement de vingt-quatre et vingt-neuf actes. Ce double tropisme s'explique aisément par la localisation de Reigny en marge des deux diocèses.

L'ermitage de Fontemoy avait été fondé dans le diocèse d'Autun; les ermites puis les premiers moines, non exemptés de la juridiction de leur ordinaire, se sont tournés vers lui pour lui faire notifier les quelques dons qu'ils avaient reçus. Installés à Reigny après 1134, les cisterciens disposaient des terres de Fontemoy et entendaient continuer à les gérer et à les accroître, d'où les contacts maintenus avec l'évêque d'Autun, principalement à l'époque d'Etienne II, entre 1171 et $1189^{43}$.

40 La terre de Reigny se trouve à proximité de Vermenton, dans le diocèse d'Auxerre. C'est l'évêque de cette cité que les moines sollicitent en cas de besoin (ils ne sont pas exemptés de sa tutelle, du moins pas avant 1184). Ils le fréquentent d'autant plus volontiers que pendant près de trente ans ce sont d'anciens cisterciens qui ont été sur ce siège : Hugues de Mâcon, ancien abbé de Pontigny (1136-1151), puis Alain de Lille, 
ancien abbé de Larivour (1152-1167) qui démissionna en 1167 pour mourir à Clairvaux en $1182^{44}$. En outre, la plupart des acquisitions des moines se fait après 1150 dans le diocèse d'Auxerre, d'abord aux alentours de l'abbaye, puis autour des granges en constitution. Ce qui justifie amplement leur attrait pour la chancellerie de cet évêque ${ }^{45}$.

\begin{tabular}{|l|}
\hline A., abbé de Saint-Pierre d'Auxerre (avec G. chantre d'Auxerre et maître R.) \\
\hline \hline X., abbé de Saint-Pierre d'Auxerre (avec X. chantre d'Auxerre) \\
\hline \hline Etienne, abbé de Reigny \\
\hline \hline Garinus, abbé de Pontigny et Girald, abbé de Clairvaux \\
\hline \hline Girard, abbé de Vézelay et Galon, abbé de Reigny \\
\hline \hline Hardouin, abbé de Saint-Germain d'Auxerre \\
\hline \hline Hedwige, abbesse de Saint-Julien \\
\hline \hline Rainard, abbé de Cîteaux (avec Hugues évêque d'Auxerre et Henri évêque de Troyes) \\
\hline \hline Pierre, abbé de Saint-Pierre d'Auxerre \\
\hline \hline Total
\end{tabular}

Tableau 6 : Les abbés auteurs des actes de Reigny.

41 Les abbés qui interviennent sont d'abord des cisterciens. Ils s'entremettent généralement pour mettre fin à de scandaleuses querelles entre deux abbayes de leur ordre. L'abbé de Cîteaux, Rainard, en compagnie des évêques d'Auxerre et de Troyes, arbitre une querelle avec Pontigny au sujet de pâturages à Villiers-la-Grange ${ }^{46}$. Les abbés Garin de Pontigny et Girard de Clairvaux, délégués par le chapitre général, interviennent en 1172 pour régler un conflit entre Bouras et Reigny ${ }^{47}$. L'autorité (ou l'aura) d'un abbé cistercien est suffisante pour qu'Etienne de Toucy, premier abbé de Reigny, ait été mis à contribution par les moines de Saint-Germain d'Auxerre. Ils lui ont demandé de notifier que la querelle opposant l'abbé de Saint-Germain aux neveux de Landry de Dracy au sujet de la terre de Sommecaise a été réglée. Il a en outre obtenu de Landry et de ses neveux la promesse de ne plus nuire à l'abbaye auxerroise ${ }^{48}$.

L'abbé et la communauté de Reigny ont des contacts fréquents avec les abbés ou abbesses de monastères dont les domaines sont solidement implantés dans le diocèse d'Auxerre. La jeune abbaye s'installe sur des terroirs déjà bien exploités par les grandes abbayes bénédictines, ce qui crée parfois des frictions. Les abbés les plus souvent approchés sont sans surprise ceux de Saint-Germain d'Auxerre et de Vézelay, de SaintPierre d'Auxerre, collégiale de chanoines réguliers, et enfin l'abbesse de Saint-Julienlès-Auxerre. Dans leurs actes, ils consignent des accords ou des échanges faits avec les cisterciens. Ces auteurs sont parties-prenantes des affaires; ils ne disposent pas d'une autorité supérieure à celle de l'abbé de Reigny, mais les cisterciens souhaitent disposer 
d'un témoignage écrit et scellé de leurs actions juridiques en cas de contestation par leurs successeurs.

Restent les princes laïcs. Il s'agit d'abord du roi de France, Philippe Auguste dont le premier acte en faveur de Reigny date de $1181^{49}$. Sont également sollicités les princes implantés dans la région à savoir le duc de Bourgogne et les comtes ou comtesses de Nevers, en bref les autorités laïques dont les vassaux sont les bienfaiteurs de Reigny. Enfin, les premiers seigneurs auteurs d'actes apparaissent à la fin du XII ${ }^{e}$ siècle, vers 1170, au moment où ils disposent enfin d'un sceau personnel, équestre de préférence : ce sont les seigneurs de Montréal ou ceux de Saint-Vérain qui sont les plus sollicités, c'est-à-dire ceux dont les terres voisinent les domaines de Reigny ${ }^{50}$.

Les évêques sont les autorités les plus sollicitées par les cisterciens pour confirmer ou notifier leurs actions juridiques. Ce phénomène est courant dans les abbayes cisterciennes: les moines blancs ne sont pas exemptés de la tutelle épiscopale; ils acquièrent la majorité de leurs biens dans le diocèse dans lequel se trouve leur monastère. Ils craignent que leurs acquisitions ne soient contestées par les donateurs ou leurs héritiers: par principe de précaution, ils fréquentent avec assiduité la chancellerie épiscopale naissante... ce qui a dû leur coûter cher ${ }^{51}$.

Des bienfaiteurs de Reigny : l'importance des contacts locaux

\begin{tabular}{|l|l|}
\hline Evêques & 7 \\
\hline \hline Abbés & 12 \\
\hline \hline Ecclésiastiques divers & 13 \\
\hline \hline Rois & 2 \\
\hline \hline Ducs/comtes & 3 \\
\hline \hline Seigneurs (dominus) & 28 \\
\hline \hline Chevaliers (miles) & 5 \\
\hline \hline Autres laïcs & 119 \\
\hline \hline Total & 189 \\
\hline
\end{tabular}

Tableau 7 : Les disposants dans les actes de Reigny

Les disposants sont majoritairement des laïcs, dont on ne sait pas toujours le statut social en l'absence d'indications précises. Certains sont des chevaliers (miles), d'autres des laïcs que l'on suppose relativement aisés, peut-être « nobles », mais rien ne permet de l'affirmer, quand seul un prénom est utilisé pour les désigner. Lorsque l'origine géographique est signalée, on s'aperçoit que ces donateurs sont originaires des finages environnants : ceux qui ont des contacts avec Reigny sont presque tous implantés au voisinage de l'abbaye et de ses terres ${ }^{52}$. Parmi eux, apparaissent quelques femmes, même si ces dernières sont davantage appelées à approuver la donation d'un père, d'un époux ou d'un frère qu'à donner elles-mêmes. Ces laïcs font des donations restreintes, 
en marge des terroirs, probablement pour ne pas se ruiner ou léser leurs héritiers. Leur stratégie de don est très prudente. Dans le même temps, les moines sont soucieux de s'assurer l'approbation des ayants-droits, qu'ils peuvent récompenser en espèces sonnantes et trébuchantes ou par des contre-dons en nature, en particulier des animaux.

Outre les dons des "simples» laïcs, les moines sollicitent ceux de seigneurs bien implantés dans la région, surtout ceux de Montréal ou de Saint-Vérain. Ces seigneurs commencent à délivrer leurs actes et à les sceller d'un beau sceau équestre à la fin du siècle. Ils y consignent aussi bien leurs propres donations, que celles de leurs vassaux, à la demande de ces derniers ou des moines.

Parmi les disposants, les princes sont un peu en retrait et s'ils donnent ce sont des portions de territoire relativement importantes en échange d'un droit de sépulture ou de messes pour le repos de leur âme ou de celle de leur parenté. Les comtes et comtesses de Nevers sont des bienfaiteurs fidèles des moines de Reigny. L'origine de cette générosité est attribuée, selon la notice de fondation de Reigny, au comte Guillaume II de Nevers qui, avant de devenir chartreux, aurait spécialement contribué à la construction et à la fondation du monastère à Reigny ${ }^{53}$. Ainsi, ce comte était intéressé par l'implantation d'un monastère cistercien en marge de ses terres, afin de mieux les contrôler. En participant à cette fondation, il souhaitait également effectuer un acte de souveraineté et s'assurer la prestigieuse renommée de fondateur d'abbaye, lui qui avait déjà contribué au soutien matériel de Pontigny ${ }^{54}$.

Enfin, les ecclésiastiques ont tendance à donner des dîmes (évêques), à procéder à des échanges de terre ou à reconnaître les droits contestés de Reigny sur des pâturages (abbés).

Comment arrondir son patrimoine? Les modes d'acquisition des biens

\begin{tabular}{|l|l|}
\hline Abandon de réclamation & 11 \\
\hline \hline Accord et jugement & 18 \\
\hline \hline Acensement et bail & 2 \\
\hline \hline Approbation & 5 \\
\hline \hline Confirmation des biens (générale ou particulière) & 13 \\
\hline \hline Donation & 69 \\
\hline \hline Echange & 3 \\
\hline \hline Exemption & 6 \\
\hline \hline Fondation & 1 \\
\hline \hline Vente & \\
\hline
\end{tabular}


\begin{tabular}{|l|l|}
\hline Total 136 \\
\hline
\end{tabular}

Tableau 8 : Les modes d'acquisition des biens par les moines de Reigny s'accompagnent d'une rétribution plus ou moins importante : un cens annuel souvent recognitif ou une somme en argent parfois importantes, voire un troupeau entier. Ces dons ressemblent à s'y méprendre à des ventes et brouillent le message des chartes par l'emploi simultané du vocabulaire de la donation et de la vente ${ }^{58}$. Par exemple, entre 1184 et 1199, Josselin d'Avallon offre, pour le salut de son âme et de ses ancêtres, aux moines de Reigny tous ses droits de pâturage sur sa terre à Arcy, des deux côtés de la Cure ${ }^{59}$. En retour, il reçoit deux cents brebis et un cheval ${ }^{60}$. Ce n'est pas le seul acte de Reigny qui contient une monture comme dédommagement d'une donation : le seigneur de Saint-Vérain et son frère en ont obtenu un en $1163^{61}$. En 1186, Rénier de Chastellux a reçu contre tout ce qu'il possédait à Tréclin un palefroi et 200 agneaux ${ }^{62}$. Ces deux échanges montrent que les moines sont assez riches pour se défaire en peu de temps d'intervalle de 400 têtes de bétail. Le problème reste la présence de chevaux dans leur monastère... Comment ces animaux sont-ils entrés en possession des moines qui n'en ont à priori aucun besoin? Reflètent-ils le rang social du donateur et son statut de chevalier?

51 Les premiers "vrais" achats des cisterciens - où le verbe vendere est employé remontent au milieu du XII ${ }^{e}$ siècle. Sept de ces achats apparaissent dans la "pancarte " déjà mentionnée ${ }^{63}$. Mes réticences face à ce document sont nombreuses puisque l'emploi du verbe vendidit peut être dû à une réécriture par le copiste.

l'écrit mis au point pour éviter les conflits peut les déclencher et provoquer par ricochet une nouvelle production documentaire. Ainsi, les premières réclamations et règlements de litige se manifestent à Reigny dans la seconde moitié du XII siècle, à un moment où les héritiers et autres ayant-droits, s'estimant lésés par les générosités du passé, s'opposent aux dons parentaux avec quelque acrimonie. Les comptes-rendus de procès conservés dans les archives du monastère contiennent des récits terminés à l'avantage des moines. Pourtant ce n'est pas toujours le cas et, en échange de leur renonciation définitive, les plaignants peuvent obtenir un dédommagement en nature ou en argent. L'abbaye avait tout intérêt à faire quelques concessions pour éviter d'envenimer la situation ou de mettre en fuite d'autres donateurs éventuels par une trop grande rigidité. Les querelles avec les autres établissements monastiques aboutissent souvent à des compromis (concordia ou pax) ou débouchent sur un arbitrage extérieur pour délimiter les possessions réciproques.

Bulletin du centre d'études médiévales d'Auxerre | BUCEMA , Collection CBMA 

aussi des bois ou des prés. La superficie de ces biens n'est jamais très importante, mais leur accumulation finit par constituer des granges de taille respectable ${ }^{64}$; outre les terres, les cisterciens cherchent à obtenir les droits pesant sur elles : dîmes ou cens. Ils souhaitent également contrôler la Cure qui coule près de l'abbaye : droits de pêche... Cette stratégie d'acquisition d'un petit territoire, noyau d'une grange, puis des terres alentours et des droits pesant sur eux est caractéristique des cisterciens et respecte à peu près les statuts de l'ordre concernant les possessions licites ${ }^{65}$.

Conclusion

Le travail de transcription et d'édition des actes de Reigny, loin d'être achevé, est prometteur. A travers ces documents, la société bourguignonne du XII ${ }^{\mathrm{e}}$ siècle peut être approchée dans sa diversité : non seulement les princes et seigneurs, comme les ducs de Bourgogne, les comtes et comtesses de Nevers, les seigneurs de Montréal ou de SaintVérain, la famille des Chastellux, mais aussi les laïcs, parfois les femmes. Les moines de Reigny sont en relation avec de nombreux établissements religieux du diocèse d'Auxerre: les abbayes cisterciennes de Pontigny ou de Bouras, mais aussi les monastères bénédictins solidement implantés comme Vézelay ou Saint-Germain d'Auxerre. Ils sont surtout en contact avec les évêques d'Autun et d'Auxerre, signe de leur installation de plus en plus forte dans ces deux diocèses.

Le nombre de documents originaux encore conservés permet d'affirmer le souci constant des moines de rédiger les actions juridiques pour ne pas en perdre la mémoire et de préserver leurs archives. Ces cisterciens sont bien les enfants de la « réforme » de l'écrit, telle qu'elle se manifeste au cours du XII ${ }^{e}$ siècle.

\section{Annexes}

\section{Charte de fondation de Fontemoy (1104)}

57 Etienne, évêque d'Autun, notifie que le chevalier Anséric d'Avallon et Gui de Noyers ont fait don en 1104 à deux ermites, Girard et Guérin, de la terre de Saint-Pierre, voisine du village de Joux. Ensuite, à la demande des ermites, les deux laïcs leur ont donné le bois qui était proche de ce lieu. L'année suivante, en présence d'Eudes, duc de Bourgogne les donateurs lui ont confirmé leur don.

58 A. Original perdu.

59 B. Archives Nationales, LL $988^{\mathrm{B}} ; B^{2}$. Copie du recueil des Archives Nationales, LL $988^{\mathrm{B}}$, par M. de Chastellux, A.D. Yonne H 1562, acte 1 p. 1.

60 a. Gallia Christiana, t. XII, Instr. Auxerre, $\mathrm{n}^{\circ}$ X. - b. Cartulaire général de l'Yonne, I, CIX, p. 208-210.

61 Note : Cet acte est la confirmation par Etienne II, évêque d'Autun de 1171 à 1189, d'un acte délivré antérieurement par son prédécesseur, Henri de Bourgogne. Ce dernier a été évêque d'Autun de 1148 à 1170-1171. En 1104, l'évêque titulaire de ce siège s'appelait Norgauldus (1098-1112). S'il s'agit d'un document "authentique», nous sommes face à une notice de fondation rédigée bien après les origines, dans le but d'en conserver la mémoire alors que les fondateurs ont depuis longtemps disparu.

D'après $B^{2}$ :

[1] Quoniam aliquando temporum vetustate seu varietate hominum solent instituta, aut oblivione, aut dolosa malignitate mutari vel everti, ideo litterarum notitia memoriæ commendare et determinare curavimus concessionem et donationem quam Ansericus, 
miles de Avalone, et Guido de Nueriis fecerunt Girardo et Warino heremitis et monachis, de terra que est prope villam que dicitur Juga, que nominatur terra Sancti Petri, quam in feodo tenebant, alter id est Ansericus, de domno Odone de Avalone; alter, id est Guido, de domno Milone de Noeriis. Predicti itaque Girardus et Warinus heremite et presbyteri secreti ab hominibus vivere volentes, et sine hominum lite et importunitate operi manuum insistere, pariterque ad dandum sibi et sociis suis victum ligonibus et aratris terram perscindere et excolere, petierunt a predictis militibus donari sibi et per eos omnibus quicumque per succedentia tempora ibi sub obtentu religionis in sancto famulatu Deo militarent, predictam terram cum silva que consita erat, quia heremitice vite conversationi et quibuslibet in sancto proposito Deo famulaturis apta videbatur et opportuna. Ipsi vero cum deliberato et premeditato apud se consilio, statuta die, hanc donationis investituram promptissima, sicut rogati fuerant, voluntate fecerunt et alacri. Ansericus quidem in manum Girardi heremite et presbyteri, hoc donum fecit apud Avalonem, nonas januarii, quinta feria, consilio et voluntate amicorum suorum et uxoris sue Marie et fratris sui Gibaudi, videntibus his quos subnotavimus: Petro canonico, Lamberto archipresbitero, Hildrado canonico, Willelmo de Domo Dei que est apud Juga, Bernardo heremitarum famulo et aliis, concedente etiam et laudante domno Odone a quo tenebat, et uxore sua Regina et filiis Arduino et Joscelino et Nocherio. Alter vero, scilicet Guido, hujus doni investituram, consilio et voluntate amicorum suorum et uxoris suæ Iceline, quam eo anno in uxorem duxerat, fecit in manum Warini heremite et presbyteri, predicti Girardi socii, xv kalendas martii, quarta feria, hiis subnotatis presentibus et videntibus: Guidone prebitero, Stephano marischalco, Rainaldo cordubanario, Warino de Colantis, concedente pariter et laudante domno Milone a quo tenebat, et uxore sua Anna, et filio suo Milone ; et ne de spatio et meta locorum hujus date terre ulla aliquando fieret dubitatio, totum ex integro dederunt, ita ut nihil omnino in aliquo retinerent ex his omnibus que habere videbantur infra publicas stratas duarum viarum, quarum una venit ab Autissiodoro, altera vadit Verzelliacum, quidquid scilicet quod eorum fuerit infra publicas quas vocant caminos includitur. Actum est hoc, ut prediximus, anno Dominice Incarnationis millesimo centesimo quarto, predictis datarum terminis et septimanarum feriis, additis testibus : Guidone Richardo, Guirardo cellerario, Willelmo fratre Lamberti archipresbiteri, Landrico Ferrabove, Henrico et jam qui testis scripsit.

[2] In sequenti quoque anno, cum pertraxatus Guido sancte Marie Magdalene solemnitate celebrata, ad propria repedaret, perscriptum donum magna mentis devotione confirmavit, et in confirmationis augmentum cartam in ejus doni auctoritate scriptam manu propria super altare predicti loci posuit, et positam sibi legi et exponi fecit. Hujus rei testes fuerunt: Milo comes de Barro, Manasses de Gesca, Fromundus canonicus, Galterius prepositus, Bonus Amicus, Hugo Allorivus.

[3] Nec est pretereundum quod, evoluto fere anni spatio postquam hec facta sunt, cum dominus Hugo, dux Burgundiæ, Avalonem venisset, supra nominati milites, Ansericus videlicet et Odo ad eum accedentes, predictam hujus terre donationem coram eo per ordinem exposuerunt. Quod ille libens accipiens sue quoque proprie concessionis et assertionis sanctione, eamdem donationem firmam et ratam in perpetuum fieri instituit, et ad memoriam posterorum scripto tradi ibidem mandavit. Hoc autem factum est quarta kalendas februarii, feria tertia, Avalone, presentibus multis nobilibus viris qui tunc ad ducis curiam convenerant, ex quibus paucos gratia testimonii hic 
subscribendos putavimus: Robertus Lingonensis episcopus, Guido Guannenricensis, Joscelinus Forus, Petrus canonicus, Ranerius et Achardus, dapiferi.

[4] Ut igitur ratum, illibatumque jure perpetuo permaneat, presentis pagine patrocinio et sigilli nostri auctoritate roboravimus.

[5] Ego Stephanus, Dei gratia Eduensis episcopus, notum fieri volo presentibus et futuris quod, sicut vidi et cognovi ex authentico scripto prædecessoris nostri bone memorie Henrici Eduensis episcopi sic attestor et firmam, illibatamque jure perpetuo permanere decerno concessionem, quam Ansericus miles de Avalone et Guido de Nuceriis fecerunt Girardo et Guarino heremitis et monachis de terra que dicitur Juga.

\section{Notice de fondation de Reigny (1134-1162)}

netice de fondation rapporte que le monastère de Reigny fut d'abord fondé à Fontemoy par deux ermites, Girard et Guérin. Il fut transféré à Reigny par l'abbé Etienne de Toucy qui mourut en 1162. Guillaume II, comte de Nevers, avant de devenir chartreux, contribua spécialement à la construction et à la fondation du monastère à Reigny.

A. Original perdu.

a. Gallia Christiana, t. XII, Instr. Auxerre, $\mathrm{n}^{\circ} \mathrm{XI}$, col. 107. - b. Cartulaire général de l'Yonne, t. I, acte 175, p. 300.

D'après $b$ :

73 Anno ab Incarnatione Domini M. cXXXIV, epacta XXIII, concurr. VII, indict. XII, feria VI ante adventum Domini, in die sancti Andreæ apostoli, Innocentio Romano pontifice II ${ }^{\circ}$, anno IV pontificatus ipsius; Hugone, Autissiodorensi pontifice ; domno Stephano de Tociaco abbate primo loci ipsius; Ludovico rege Francorum; Guillelmo Nivernensi comite qui etiam locum ipsum comparavit, fundavit et ædificavit, ac postea Carthusiam profectus, atque ibidem Deo serviens defunctus est. Fuit autem ipsa abbatia de Regniaco antea apud Fontesmum, sub eodem venerabili patre, per septem fere annos; ex eo scilicet tempore quo ibi ordo Cisterciensis advenerat. Hujus authores ab initio fuerunt sanctissimi et religiosissimi viri domnus Girardus et domnus Garinus, quorum unus in abbatem, quamvis invitus, sublimatus, alter vero in priorem electus est; qui ibidem cum multis fratribus, longo tempore, Deo servientes cursum vitæ suæ feliciter impleverunt. Horum itaque successores, supradictus, scilicet, abbas Stephanus quartus a beato Girardo cum suis posteaquam abbatiam Regniacum transtulerunt, memores sanctæ conversationis illorum die III, id est IV nonas decembris, die dominica postquam ibi advenerant, mittentes, detulerunt corpora eorum, et in capitulo quasi patronos in uno sepulchro honorifice condiderunt. Tenuit autem idem venerabilis Stephanus abbatiam apud Fontismum annis sex, et mensibus fere tribus, apud Regniacum vero XXVII annis, mensibus sex; qui simul juncti fiunt xxxIII cum supradictis diebus completisque annis LXII nativitatis suæ, VII kalendas junii, in vigilia Pentecostes, diem clausit extremum anno ab Incarnatione Domini M. CLXII, flentibus nobis et desolatis.

\section{3. « Pancarte » de Reigny (1151 [ ?])}

Eudes de Lichères, avec l'approbation de son fils et de son épouse, de Martin Delfor, de Brictinus et de Pierre, de Marie, épouse de Gui, de Gibols et de ses proches, des chanoines de Châtel-Censoir, de Cremburs, de son fils et de sa fille. 

Gaufridus, Arnaldus et Tancredus et Ceters canonici, et Andreas de la Palu et Aelez uxor ejus de cujus capite erat, laudante Bernardo cognato suo et filiastris Helisabetsh et Gilla. Hujus rei testes sunt: Gaufridus canonicus, Huldrinus tunc capellanus Castro Censurii, Joffroes Birtinis, Johannes Arnalis, Stephanus famulus noster, Aimbertus, Briccius de Lescheriis, Johannes de Burvon, Willelmus de Crey, Ricardus sororius Odonis, Galterius de Feelin, Rainals Bonamie, Petrus dux, Dodo Choris qui dedit nobis quicquid habebat in valle Berterin.

85 [7] De laudatione filistrarum Andreae de la Palu testes sunt: Raimruus Bergirs, Stephanus, Gaufridus de Sancta Salvatore, Johannes, Arnaldus, Aimcus Libats et frater ejus Birals de Catsro censurii.

86 [8] De laudatione Wiburs et filiarum ejus testes sunt : Petrus clericus de Turre, Galterius Folirs, Rainals Birals, Stephanus Ricars.

87 [9] De Valle Bertirin vendidit nobis octavam partem Cremburs et Gaufridus filius ejus et filia Floris et Dodo maritus suus. Hujus rei testes sunt: Huldreus capellanus illo tempore Castro censurii et Helvebertus faber de Clamici, Brecceus et Bovo sororius Soembaldi de Lescheriis et Lambertus Girars.

88 4. Les deux chirographes ou les deux exemplaires d'un même chirographe? Les actes de 1172 


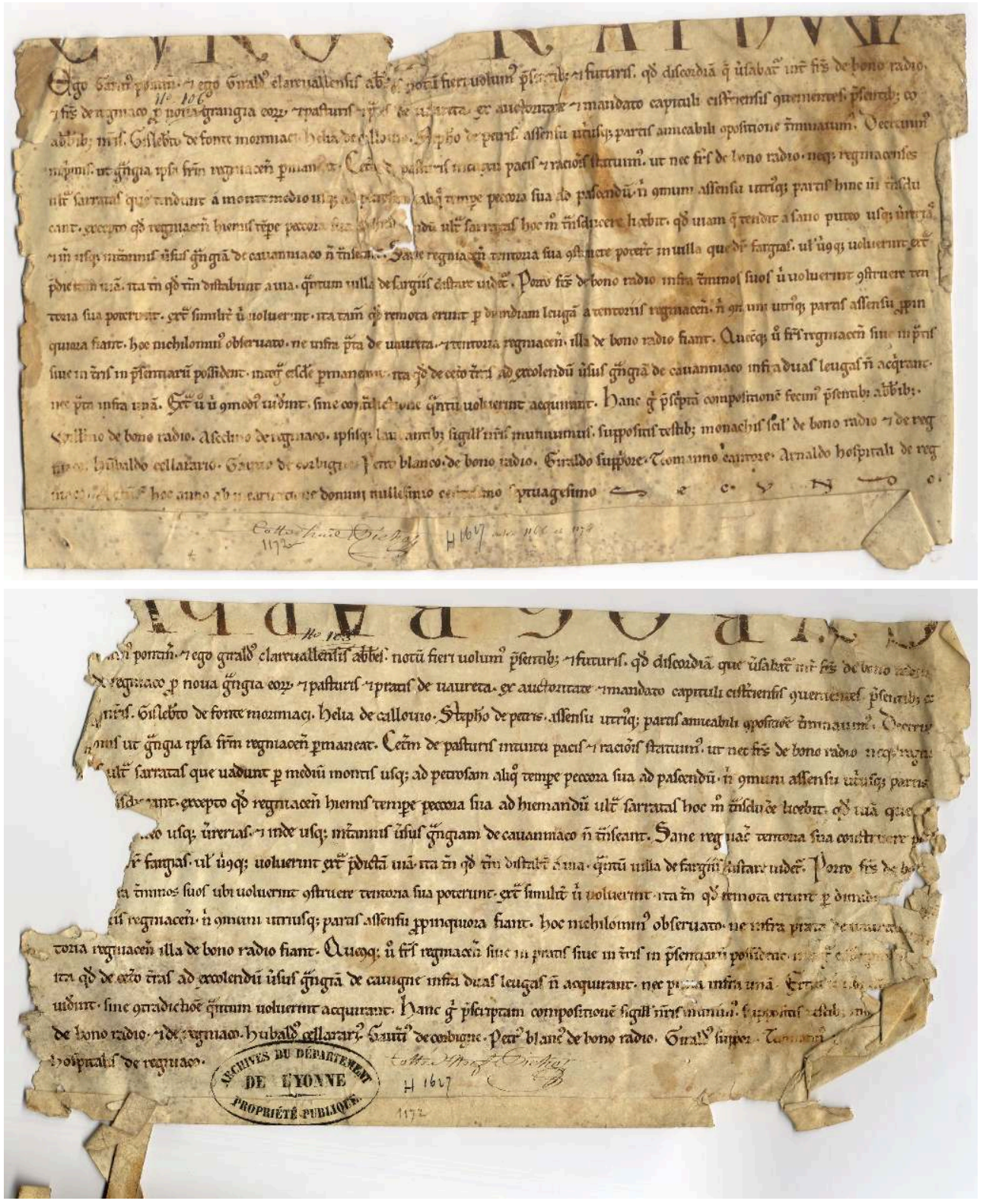

Clichés, AD Yonne, $\mathrm{H} 1627$

Garin, abbé de Pontigny, et Giraud, abbé de Clairvaux, interviennent comme arbitres pour mettre fin à un conflit opposant les moines de Reigny à ceux de Bouras concernant la grange de Vaureta, bâtie par les moines de Reigny.

Transcription de la partie 1 :

A. Original. A.D. Yonne, H 1627. Partie inférieure d'un chirographe autrefois scellée. Devise cyrographum.

a. Cartulaire général de l'Yonne, t. II, acte 222, p. 237-238

Mention : Inventaire dressé par M. de Chastellux, A.D. Yonne, H 1562-3, Grange-Sèche, acte 4 (daté de 1170)

Note : Guillaume, abbé de Bouras, et Ascelin, abbé de Reigny, approuvent cet accord.

D'après $A$ : 

presentibus et futuris quod discordiam que versabatur inter fratres de Bono Radio [2] et fratres de Regniaco, pro nova grangia eorum et pasturis et pratis de Vaureta, ex auctoritate et mandato capituli cisterciensis convenientes, presentibus co-[3]-abbatibus nostris Gisleberto de Fonte Moriniaci, Helia de Callovio, Stephano de Petris, assensu utriusque partis, amicabili compositione terminavimus. Decrevimus [4] in primis ut grangia ipsa fratrum Regniacensium permaneat. Ceterum de pasturis, intuitu pacis et racionis, statuimus ut nec fratres de Bono Radio, neque Regniacenses, [5] ultra sarratas que tendunt a monte medio usque ad petrosam, aliquo tempore, pecora sua ad pascendum, nisi communi assensu utriusque partis, hinc inde transdu-[6]-cant, excepto quod Regniacensibus, hiemis tempore pecora sua ad hiemandum ultra sarratas hoc modo transducere licebit; quod viam que tendit a Sano Puteo usque Verrerias [7] et inde usque Interannis, versus grangiam de Cavanniaco non transeant. Sane Regniacenses tentoria sua construere poterunt in villa que dicitur Fargias, vel ubicunque voluerint, extra [8] predictam viam, ita tamen quod tantum distabunt a via quantum villa de Fargiis distare videtur. Porro fratres de Bono Radio infra terminos suos, ubi voluerint, construere ten-[9]-toria sua poterunt, extra similiter ubi voluerint, ita tamen quod remota erunt per dimidiam leugam a tentoriis Regniacensibus, nisi communi utriusque partis assensu propin-[10]-quiora fiant. Hoc nichilominus observato, ne infra prata de Vaureta et tentoria Regniacensia, illa de Bono Radio fiant. Quecunque vero fratres Regniacenses, sive in pratis, [11] sive in terris, in presentiatum possident, integra eisdem permaneant, ita quod de cetero terras ad excolendum versus grangiam de Cavanniaco infra duas leugas non acquirant, [12] nec prata infra unam. Extra vero, ubi commodius viderint, sine contradictione, quantum voluerint, acquirant. Hanc igitur prescriptam compositionem fecimus, presentibus abbatibus [13] Willelmo de Bono Radio, Ascelino de Regniaco, ipsisque laudantibus, sigillis nostris munivimus, suppositis testibus monachis scilicet de Bono Radio et de Reg-[14]-niaco : Humbaldo, cellerario ; Gauterio de Corbignei ; Petro Blanco, de Bono Radio ; Giraldo, suppriore ; Teomanno, cantore; Arnaldo, hospitali de Reg-[15]-niaco. Actum est hoc, anno ab Incarnatione Domini millesimo centesimo septuagesimo secundo ${ }^{67}$.

Transcription de la partie 2 :

A. Original. A.D. Yonne, H 1627. Partie supérieure d'un chirographe autrefois scellée. Devise cyrographum.

\section{D'après A :}

[Ego Garinus] Pontiniacensis et ego Giraldus Clarevallensis abbates, notum fieri volumus presentibus et futuris quod discordiam que versabatur inter fratres de Bono radio et [2] [fratres] de Regniaco, pro nova grangia eorum et pasturis et pratis de Vaureta, ex auctoritate et mandato capituli Cisterciensis convenientes, presentibus [3] [coabbatibus] nostris Gisleberto de Fonte Moriniaci, Helia de Callovio, Stephano de Petris, assensu utriusque partis, amicabili compositione terminavimus. Decrevi-[4][mus in primis] ut grangia ipsa fratrum Regniacensium permaneat. Ceterum de pasturis, intuitu pacis et racionis, statuimus ut nec fratres de Bono radio, neque Regniacenses [5] ultra sarratas que vadunt per medium montis usque ad petrosam aliquo tempore peccora sua ad pascendum, nisi communi assensu utriusque partis [6] [hinc inde] [trans]ducant, excepto quod Regniacensibus hiemis tempore peccora sua ad hiemandum ultra sarratas hoc modo transducere licebit ; quod viam que [tendit] [7] [a Sano put]eo usque Verrerias et inde usque Interannis versus grangiam de Cavanniaco 
non transeant. Sane Regniacenses tentoria sua construere p[oterunt in] [8] [ villa que dicitur] Fargias vel ubicumque voluerint extra predictam via, ita tamen quod tantum distabunt a via, quantum villa de Fargiis distare videtur. Porro fratres de Bo[no radio] [9] [infra] terminos suos, ubi voluerint, construere tentoria sua poterunt, extra similiter ubi voluerint, ita tamen quod remota erunt per dimidi[am leugam] [10] [ a tentor]iis Regniacensibus, nisi communi utriusque partis assensu propinquiora fiant. Hoc nichilominus observato, ne infra prata de Vaureta [et ten-] [11]-toria Regniacensia, illa de Bono radio fiant. Quecumque vero fratres Regniacenses sive in pratis, sive in terris in presentiatum possident, integra [eidem permaneant,] [12] ita quod de cetero terras ad excolendum versus grangiam de Cavigne infra duas leugas non acquirant, nec pr[at]a infra unam. Extra vero, [ubi commodius] [13] viderint, sine contradictione quantum voluerint, acquirant. Hanc igitur prescriptam compositionem sigillis nostris munivimus, suppositis testibus [monachis scilicet] [14] de Bono radio et de Regniaco : Humbaldus cellerarius, Gauterius de Corbione, Petrus Blancus de Bono radio, Giraldus supprior, Teomannus [cantor, Arnaldo] [15] hospitalis de Regniaco.

\section{Les raisons des actions juridiques}

\begin{tabular}{|c|c|}
\hline Cote & Motif de l'action juridique \\
\hline AD Yonne 1577 & ... ex mandato domni pape \\
\hline $\begin{array}{l}\text { AD Yonne } \mathrm{H} \\
1562\end{array}$ & ... cupiens de seculari conversationead religiosam transire vitam \\
\hline $\begin{array}{l}\text { AD Yonne } \mathrm{H} \\
1562-2\end{array}$ & ... ad censum siquidem duorum solidorum \\
\hline $\begin{array}{l}\text { AD Yonne H } \\
1562\end{array}$ & ... cum Ludovico rege Francorum, multisque aliis pergeret Jerosolymam \\
\hline $\begin{array}{l}\text { AD Yonne } \mathrm{H} \\
1562\end{array}$ & ... decem solidis Autisiodorensis monete \\
\hline $\begin{array}{l}\text { AD Yonne H } \\
1562\end{array}$ & ... divina pietate \\
\hline $\begin{array}{l}\text { AD Yonne } \mathrm{H} \\
1562\end{array}$ & ... pro damno quod eis intulerant in grangia de Cals \\
\hline $\begin{array}{l}\text { AD Yonne } \mathrm{H} \\
1562\end{array}$ & $\begin{array}{l}\text {... quoniam fraternae caritatis vinculum exigit ut fratres nostros tanquam nos } \\
\text { ipsos diligamus }\end{array}$ \\
\hline $\begin{array}{l}\text { AD Yonne } \mathrm{H} \\
1564\end{array}$ & $\begin{array}{l}\text {... divine pietatis intuitu et ob remedium anime karissimi patris nostri Ludovici, } \\
\text { bone memorie, et predecessorum nostrorum }\end{array}$ \\
\hline
\end{tabular}




\begin{tabular}{|c|c|}
\hline $\begin{array}{l}\text { AD Yonne } \mathrm{H} \\
1565\end{array}$ & ... habitis de beneficio domus Regniaci XVI libris Pruviniensibus \\
\hline $\begin{array}{l}\text { AD Yonne H } \\
1565\end{array}$ & ... LXXX libras Autisiodorensis monete \\
\hline $\begin{array}{l}\text { AD Yonne } \mathrm{H} \\
1565\end{array}$ & ... pour la célébration de son anniversaire \\
\hline $\begin{array}{l}\text { AD Yonne } \mathrm{H} \\
1565\end{array}$ & $\begin{array}{l}\text {... pro salute anime sue et animabus patris et matris sue et antecessorum } \\
\text { suorum }\end{array}$ \\
\hline $\begin{array}{l}\text { AD Yonne } \mathrm{H} \\
1565\end{array}$ & $\begin{array}{l}\text {... pro salute anime sue et antecessorum suorum; de beneficio domus Regniaci, } \\
\text { ducentas oves et unum equum }\end{array}$ \\
\hline $\begin{array}{l}\text { AD Yonne } \mathrm{H} \\
1566\end{array}$ & $\begin{array}{l}\text {... pro anima sua et uxoris suae Agnetis et pro animabus antecessorum suorum ; } \\
\text { ducentos agnos et unum palefridum }\end{array}$ \\
\hline $\begin{array}{l}\text { AD Yonne } \mathrm{H} \\
1566\end{array}$ & ... pro salute animarum suarum \\
\hline $\begin{array}{l}\text { AD Yonne } \mathrm{H} \\
1566\end{array}$ & ... pro salute anime sue et antecessorum suorum \\
\hline $\begin{array}{l}\text { AD Yonne } \mathrm{H} \\
1566\end{array}$ & ... pro suis etiam peccatis, cum regali exercitu ire Jherusalem \\
\hline $\begin{array}{l}\text { AD Yonne } \mathrm{H} \\
1566\end{array}$ & $\begin{array}{l}\text {... quando Pontius miles de Petra Pertusa reddidit se Deo et beate Marie et } \\
\text { fratribus de Regniaco }\end{array}$ \\
\hline $\begin{array}{l}\text { AD Yonne } \mathrm{H} \\
1577\end{array}$ & ... pro anime sue remedio \\
\hline $\begin{array}{l}\text { AD Yonne } \mathrm{H} \\
1577\end{array}$ & $\begin{array}{l}\text {... pro salute anime mee et Beatricis uxoris mee et pro animabus patris et matris } \\
\text { mee fratrumque meorum }\end{array}$ \\
\hline $\begin{array}{l}\text { AD Yonne H } \\
1577\end{array}$ & ... pro salute anime sue, uxoris, filiorum et filiarum et antecessorum suorum \\
\hline $\begin{array}{l}\text { AD Yonne } \mathrm{H} \\
1588\end{array}$ & $\begin{array}{l}\text {... pro salute anime sue... cum reddidit se inter manus Ascelini, venerabilis } \\
\text { abbatis de Regniaco, fratrum collegio cum vellet sociandus et eorum beneficiis } \\
\text { et orationibus communicandus }\end{array}$ \\
\hline $\begin{array}{l}\text { AD Yonne } \mathrm{H} \\
1604\end{array}$ & ... pro anima sua et antecessorum suorum \\
\hline $\begin{array}{l}\text { AD Yonne } \mathrm{H} \\
1604\end{array}$ & ... pro salute animarum nostrarum et antecessorum nostrorum \\
\hline
\end{tabular}




\begin{tabular}{|c|c|}
\hline $\begin{array}{l}\text { AD Yonne } \mathrm{H} \\
1609\end{array}$ & ... pro salute nostra et antecessorum nostrorum \\
\hline $\begin{array}{l}\text { AD Yonne H } \\
1615\end{array}$ & ... pacem \\
\hline $\begin{array}{l}\text { AD Yonne } \mathrm{H} \\
1615\end{array}$ & ... pro salute anime sue et antecessorum suorum \\
\hline $\begin{array}{l}\text { AD Yonne } \mathrm{H} \\
1622\end{array}$ & ... pro animabus virorum suorum et pro anima sua \\
\hline $\begin{array}{l}\mathrm{AD} \text { Yonne } \mathrm{H} \\
1627\end{array}$ & ... contre une somme d'argent \\
\hline $\begin{array}{l}\text { AD Yonne H } \\
1627\end{array}$ & ... ex auctoritate et mandato capituli Cisterciensis \\
\hline $\begin{array}{l}\mathrm{AD} \text { Yonne } \mathrm{H} \\
1627\end{array}$ & $\begin{array}{l}\text {... me participem omnium orationum suarum et beneficiorum que fierent in } \\
\text { Domino }\end{array}$ \\
\hline $\begin{array}{l}\text { AD Yonne } \mathrm{H} \\
1627\end{array}$ & ... perceptis per hoc quingentis solidis et equo uno \\
\hline $\begin{array}{l}\text { AD Yonne } \mathrm{H} \\
1627\end{array}$ & ... pro salute animarum suarum et antercessorum suorum \\
\hline $\begin{array}{l}\text { AD Yonne } \mathrm{H} \\
1627\end{array}$ & ... pro salute anime suae et antecessorum suorum \\
\hline $\begin{array}{l}\text { AD Yonne } \mathrm{H} \\
1627\end{array}$ & ... contre quatorze livres de Provins \\
\hline $\begin{array}{l}\mathrm{AD} \text { Yonne } \mathrm{H} \\
1633\end{array}$ & ... amica et concordi pace \\
\hline $\begin{array}{l}\text { AD Yonne } \mathrm{H} \\
1633\end{array}$ & ... in die qua Ascelinus vir ejus tumulatus fuerat \\
\hline $\begin{array}{l}\mathrm{AD} \text { Yonne } \mathrm{H} \\
1633\end{array}$ & ... pro remedio anime mee et pro anniversario meo in abbacia Regniaci \\
\hline $\begin{array}{l}\mathrm{AD} \text { Yonne } \mathrm{H} \\
1640\end{array}$ & ... pour obtenir l'association aux œuvres spirituelles \\
\hline AN LL988B & ... ex mandato domni pape \\
\hline AN LL988B & ... pro salute animarum tam nostrarum quam antecessorum \\
\hline
\end{tabular}




\begin{tabular}{|c|c|}
\hline $\begin{array}{l}\text { BM Auxerre ms } \\
161 \mathrm{G} \text { fol. } 85 \mathrm{r}\end{array}$ & ... concordia \\
\hline $\begin{array}{l}\text { BnF ms lat } \\
17725\end{array}$ & ... contre un cens \\
\hline $\begin{array}{ll}\text { BnF ms lat } \\
17725\end{array}$ & ... cum egrotaret de infirmitate qua et mortuus est \\
\hline
\end{tabular}

\section{NOTES}

1. Charte de fondation de Fontemoy : AD Yonne, H 1562, acte 1 p. 1. Maximilien QUANTIN, Cartulaire général de l'Yonne, t. I, acte 109 p. 208-210; notice de fondation de Reigny : IBID., acte 175, p. 300. Ces deux actes, placés en annexe de ce travail, illustrent le processus d'institutionnalisation de ce monastère au début du XII ${ }^{\mathrm{e}}$ siècle et le travail de mémoire opéré par les cisterciens après 1134. Le problème est que ces deux documents ne nous sont pas parvenus sous leur forme originale... ce qui peut laisser soupçonner une réécriture des origines (qui n'est pas obligatoirement frauduleuse). Notice sur Reigny dans : Léopold JANAUSCHEK, Originum Cisterciensum, t. I, Vienne, 1877, p. 15. 2. Un monastère dédié à sainte Marie apparaît dans un acte daté de 1127-1128 et conservé sous sa forme originale (AD Yonne H 1620), Joubert Chapel donne alors sa terre de Reigny aux fratribus sancte Marie de Fontismo. Il s'agit probablement des premiers cisterciens venus s'installer à Fontemoy.

3. René LOCATELLI, «L'expansion de l'ordre cistercien », dans Bernard de Clairvaux. Histoire, mentalités, spiritualité, p. 125-126 et 132.

4. Alexis GRELOIS (éd.), Galand de Reigny. Petit livre de proverbes. Introduction, texte critique, traduction notes et index, Paris, Editions du Cerf, 1998, 229 p. (Sources chrétiennes, $\mathrm{n}^{\circ}$ 436), p. 15-16.

5. Notice de fondation de Reigny : Maximilien QUANTIN, Cartulaire..., t. I, [note 1], acte 175, p. 300.

6. A.D. Yonne, H 1561 à 1643.

7. Archives nationales, L $965, \mathrm{n}^{\circ} 52$; répertoire des archives de l'abbaye de Reigny (1753) : LL 988 ${ }^{\mathrm{B}}$.

8. Acquis par la Bibliothèque nationale de France, ce cartulaire a été retrouvé en 1912 par le comte de Chastellux selon le Bulletin de la société des sciences historiques et naturelles de l'Yonne, 66, 3e partie, 1912, séance du 3 mars 1912, p. XXIV. Henri STEIN, Bibliographie générale des cartulaires français ou relatifs à l'histoire de France, Paris, 1907, n³146, p. 431. 9. Marlène HELIAS-BARON, Recherches sur la diplomatique cistercienne au XII ${ }^{e}$ siècle. La Ferté, Pontigny, Clairvaux, Morimond, Thèse soutenue à Paris I en décembre 2005, p. 18-20. $47 \%$ d'originaux à La Ferté et $57 \%$ à Morimond. 
10. Jean-Luc BENOÎT, Pontigny, saint Edme, les moines et leurs voisins. L'abbaye cistercienne pendant la première moitié $d u X^{X I I I^{e}}$ siècle, Paris, 1997, p. 40, graphique ${ }^{\circ} 1$. Elke GOEZ, Pragmatische Schriftlichkeit und Archivpflege der Zisterzienser. Ordenszentralismus und regionale Vielfalt, namentlich in Franken und Altbayern (1098-1525), Münster - Hambourg Londres, 2003, p. 5-6.

11. Par exemple, le préambule de la charte de fondation de Fontemoy en 1104 [AD Yonne, H 1562, acte 1 p.1] stipule que : Quoniam aliquando temporum vetustate seu varietate hominum solent insituta, aut oblivione, aut dolosa malignitate mutari vel everti, ideo litterarum notitia memorie commendare et determinare curavimus...

12. Tous les originaux contenus dans le fonds de Reigny sont ou ont été scellés.

13. Olivier GUYOTJEANNIN, Jacques PYCKE et Benoît-Michel TOCK, Diplomatique médiévale, Turnhout, 1993, p. 286.

14. Le vidimus d'un acte d'Hugues de Mâcon, évêque d'Auxerre, daté de 1149, fait en 1277 par l'official d'Auxerre [AD Yonne H 1618] ; un vidimus d'une notice concernant une donation de Geoffroy d'Arcy fait par l'évêque d'Auxerre au cours du XIII ${ }^{\mathrm{e}}$ siècle [AD Yonne, H 1577] ; un vidimus d'un acte de 1154 fait en 1485 par le prévôt de Bétry et de Vermenton [AD Yonne, H 1622] ; un vidimus d'une confirmation générale des biens de Reigny par Alexandre III fait en 1450 par le garde du scel de la prévôté de Vermenton [AD Yonne, H 1563] ; un vidimus fait en 1489 par le garde du scel de la prévôté de Vermenton [AD Yonne, H 1565]; un vidimus de 1477 fait par le garde du scel de la prévôt de Bétry et Vermenton [AD Yonne, H 1604] ; deux vidimus faits en 1254 par l'évêque de Paris et par Alphonse de Poitiers (perdu) reprenant des exemptions offertes par Philippe Auguste en 1181 [AD Yonne, H 1564] ; un vidimus daté de 1217 au nom d'Eudes III, duc de Bourgogne [AD Yonne, H 1565] ; un vidimus daté de 1323 [AD Yonne, $H$ 1633] ; un vidimus de la confirmation générale des biens émanée d'Innocent III en 1199 fait en 1413 par les gardes du scel de la prévôté de Mailly-le-Château [AD Yonne, H 1563] ; un dernier vidimus du XIII ${ }^{\mathrm{e}}$ siècle venant de l'official d'Auxerre [AD Yonne $\mathrm{H}$ 1640].

15. Le premier vidimus est la copie authentique d'une notice relatant une donation de Geoffroy d'Arcy aux bénédictines de Crisenon [AD Yonne, H 1577] ; le deuxième contient une donation du duc de Bourgogne, Hugues III, vidimée en 1217 par le duc Eudes III [AD Yonne H 1565] ; le troisième contient une donation par un seigneur de Saint-Vérain vidimée par l'official d'Auxerre après 1277 [AD Yonne, H 1640]. 16. Le premier vidimus est la copie d'un acte datant de 1142. Il a été fait en 1485 [AD Yonne, H 1622] ; le second contient un acte daté de 1176. Il a été fait en 1477 [AD Yonne, H 1604].

17. Paris, BnF, ms. lat. 17725 , fol. 1-1v, fol. 3 , fol. 4 et fol. 5 .

18. Paris, BnF, ms. lat. 9887 , fol. 6 , acte 45 . Martine GARRIGUES, Le premier cartulaire de l'abbaye cistercienne de Pontigny (XII ${ }^{e}$-XIII ${ }^{e}$ siècle), Paris, 1981, acte 45, p. 118.

19. Cartulaire de l'abbaye Saint-Germain d'Auxerre, 1266, BM Auxerre, ms. 161G, fo $85 \mathrm{r}$, De Summa casa, acte VII ; titre : De terra Landrici de Draciaco apud Sanctum casium. Noëlle Deflou-Leca avait déjà remarqué cette particularité en 1997. Voir Noëlle DEFLOU-LECA, " L'élaboration d'un cartulaire au XIII ${ }^{\mathrm{e}}$ siècle : le cas de Saint-Germain d'Auxerre ", Revue Mabillon, t. 8 (=t. 69), 1997, p. 183 : «Les fonds des abbayes voisines de Pontigny, Reigny et Saint-Marien, avec lesquelles Saint-Germain a passé des transactions, viennent compléter cette maigre documentation de première main avec cinq actes qui furent copiés dans le grand cartulaire de Saint-Germain ». 
20. Un acte conservé dans le fonds de Pontigny daté de 1209 [AD Yonne, H 1428] et copié par M. de Chastellux [AD Yonne, H 1562, acte 8, p. 13-14] mentionne le règlement précédent en précisant qu'il a été donné : sub cyrographo. Le texte complet de l'affaire reprend en partie le dispositif de l'acte de 1145-1151 :... conquerebantur Regniacenses quod pastores Pontiniacensium cum animalibus suis transgrediebantur metas statutas a felicis memorie patribus nostris domno Hugone Autissiodorensi et domno Henrico Trecensi episcopis, et domno Renaudo abbate Cisterciensi, contra cartam et constitutionem eorum licet per annos quinquaginta a partibus hinc inde constitutiones ille observate fuissent et in grangiis constitutis cartarum et constitutionum transgressores sepe satisfecissent et ibidem puniti fuissent, ex eo etiam quod a tantis viris constitutiones ille sub cyrographo date fuissent, constanter eliciebant compromissum partium vel consensum qui in carta pretermissus videbatur.

21. AD Yonne, H 1562-2.

22. En particulier les préambules et les listes de témoins.

23. Jean LEBEUF [1687-1760], Mémoires concernant l'histoire civile et ecclésiastique d'Auxerre et de son ancien diocèse continues jusqu'à nos jours; avec addition de nouvelles preuves et annotations par M. Challe, M. Quantin, Auxerre, 1848-1855, 4 vol. Noëlle DEFLOU-LECA, «L'abbaye Saint-Germain », Bulletin du Centre d'études médiévales d'Auxerre, Les cartulaires bourguignons, http://cem.revues.org/document2642.html, notes 140 et 141 .

24. Archives nationales, LL $988^{\mathrm{B}}$

25. Bulletin de la société des sciences historiques et naturelles de l'Yonne, 66, $3^{\mathrm{e}}$ partie, 1912, séance du 3 mars 1912, p. XXIV.

26. AD Yonne, $\mathrm{H}$ 1561. Cet inventaire recense 418 documents délivrés entre 1100 et 1694. Reste un acte dont la tradition ne remonte qu'à Maximilien Quantin. Pour l'instant, il m'a été impossible de déterminer où il l'avait trouvé.

27. Les fonds des abbayes de Saint-Germain d'Auxerre et de Pontigny ont déjà été sondés.

28. 54 actes n'ont pas pu encore être datés avec précision...

29. AD Yonne, H 1562-2.

30. AD Yonne, H 1562-2. Voir le texte de cette « pancarte » en annexe.

31. AD Yonne, H 1588 [1169] ; H 1627 [1169-1175] ; H 1627 [1172, avec les deux parties] ; H 1633 [1180].

32. AD Yonne, H 1627.

33. Voir les deux textes en annexe. Les deux exemplaires originaux ont le même nombre de lignes, la même mise en page, ce qui laisse penser qu'il s'agit d'un même chirographe.

34. Tous les actes conservés sous leur forme originale conservent soit la trace d'un scellement, soit un sceau ou des fragments.

35. AD Yonne, H 1562-2, acte 8, p. 15-16.

36. Bernard JACQUELINE, Episcopat et papauté chez saint Bernard de Clairvaux, Saint-Lô, 1975, p. 69-70 [à propos de l'amitié entre Bernard de Clairvaux et du chancelier Haimeric, chanoine régulier de Saint-Jean-de-Latran] ; p. 72 et 79. Colin MORRIS, The discovery of the Individual 1050-1200, London, 1972, p. 104. Franz-Joseph SCHMALE, Studien zum Schisma des Jahres 1130, Cologne, 1961, p. 262. Mary STROLL, The Jewish pope. Ideology and Politics in the Papal Schism of 1130, Leiden, 1987, p. 9.

37. AD Yonne, H 1562-2, acte 9, p. 17-18.

38. Bernard de Clairvaux rédigea pour Eugène III le De consideratione [De consideratione libri V ad Eugenium papam III, juxta editionem benedictam as SS. D. N. Clementem XI dictam, 
Paris, 1918, Prologus, p. 1 : Subit animum dictare aliquid, quod te, Papa beatissime Eugeni, vel aedificet, vel delectet, vel consoletur].

39. Maximilien QUANTIN, Cartulaire..., t. I, acte 282, p. 435-436. AD Yonne, H 1563 :

Terram videlicet qua Carbonerice nuncupatur in Covensi parochia; terram et prata quce dederunt vobis Milo de Noeriis et Ansericus de Monte regali infra hos terminos, rupem videlicet Ogerii et villam Tormentiaci; territorium grangice Carbonerice quod dedit vobis Ansericus de Monte regali et Theobaldus de Scutignei; terram de Cavannis, quam dederunt vobis filii Niardi et filii Erardi de Mongalei, et Fromundus de Rufiaco ; prata quac habetis a canonicis sancti Lazari de Avalone; prata et quidquid juris habetis in bosco Carbonerice ab Anserico de Monteregali ; ex dono Landrici de Praiaco, terram Ulduni, cultam et incultam ; ex dono filii Galteri de Turre, nemus quod ex una parte dicitur Fagineus, et ex altera Sagitta; ex dono Anserici de Tarel et Guidonis de Curte, terram Fortumenserii cultam et incultam; ex dono Ascelini de Castro Censurii, terram de Porliaco et terram de Exsard cultam et incultam ; ex dono Uldoeri et Gerardi fratris ejus, terram de Leiserio, cultam et incultam, sicut metis et signis divisa esse dinoscitur ; terram quam dedit vobis Joscelinus de Arserio, in territorio Rainiaci ; ex dono Josberti Capelli et Hugonis de Castro-Censurii et Gibaldi terram ; ex dono Guillelmi comitis Nivernensis, aquam a Fonte roboris usque ad perreriam Bellimontis; ex dono Gaufridi de Dunziaco, terram de Lescheriis; terram de Chaillo, quam emistis a liberis hominibus qui eam tenebant. 40. Maximilien QUANTIN, Cartulaire..., t. II, acte 156, p. 171-175. AD Yonne, H 1563 : In quibus hec propriis duximus exprimenda vocabulis : locum in quo ipsa abbatia sita est, cum grangia que in eodem territorio est, et aliis grangiis, Fontismo videlicet, Ulduno, Essarz, Carboneriis, Lescheriis, Calcz, Bellovidere.

41. AD Yonne, H 1563.

42. AD Yonne, H 1563.

43. Concernant les premiers actes de Fontemoy, la statistique est quelque peu brouillée par leurs confirmations faites entre 1171 et 1189 par Etienne II, évêque d'Autun, à la demande des cisterciens. Comme ils concernent un domaine situé dans le diocèse d'Autun, les moines se sont tournés vers le prélat titulaire.

44. Michel SOT (dir.), Les gestes des évêques d'Auxerre, t. II, Paris, 2006, p. 19. Bernard JACQUELINE, Episcopat et papauté..., p. 150.

45. Alain de Larivour a notifié dix-huit actes entre 1152 et 1167.

46. Cartulaire de Pontigny. Paris, BnF, ms. lat. 9887, fol. 6, acte 45.

47. AD Yonne, H 1627.

48. Grand cartulaire de l'abbaye Saint-Germain d'Auxerre, 1266, BM Auxerre, ms. 161G, fo 85 r, De Summa casa, acte VII ; titre : De terra Landrici de Draciaco apud Sanctum casium.

49. AD Yonne H 1564. L'acte est conservé sous sa forme originale. Philippe Auguste exempte les moines de Reigny des taxes et autres péages sur les terres de son domaine. Ce privilège a paru suffisamment important aux moines pour qu'ils le fassent vidimer en 1254, puis qu'ils en conservent deux copies. En 1195, le roi ordonne qu'aucun juge public ni aucun prévôt ne demande aux moines de Reigny aucun droit de péage, aucune coutume. Il leur accorde pleine liberté de circuler sur ses terres. Cet acte n'est connu que par sa mention sur l'inventaire de M. de Chastellux [AD Yonne, H 1562-3].

50. Un laïc non titré et sans réelle autorité donne un acte en son nom. Il s'agit de Guillaume de Tilly qui approuve en 1120 une donation faite par son vassal Landry de Prey. Par sa date précoce, cet acte peut sembler douteux, d'autant qu'il n'est connu que par sa transcription faite au XVII ${ }^{\mathrm{e}}$ siècle : AD Yonne H 1562-2, acte 1, p. 1.

51. Si les moines rédigent eux-mêmes leurs actes, ils doivent néanmoins payer le sceau épiscopal. 
52. Avallon, Noyers, Arcy-sur-Cure, Saint-Vérain, Vermenton, Montréal...

53. Maximilien QUANTIN, Cartulaire..., t. I, [note 1], acte 175, p. 300

54. Martine GARRIGUES, Cartulaire de Pontigny, acte 84, p. 152-154.

55. Laurent FELLER, « Les politiques familiales des familles aristocratiques à l'égard des églises en Italie centrale (IX ${ }^{\mathrm{e}}-\mathrm{XI}^{\mathrm{e}}$ siècles) », dans Sauver son âme et se perpétuer.

Transmission du patrimoine et mémoire au haut Moyen Âge, sous la direction de François Bougard, Cristina La Rocca et Régine Le Jan, Rome, 2005, p. 267.

56. Un acte de Geoffroy de Saint-Vérain, datable des années 1180-1192, est intéressant à ce propos [AD Yonne, H 1627]. Les moines ont associé ce seigneur au bénéfice de leurs prières et ils lui ont promis de chanter sa vie durant une messe annuelle du Saint-Esprit et, après sa mort, une messe des défunts. En échange, il leur a donné huit sous et demi de cens et trois setiers d'avoine qu'il prenait sur leur grange de Ville-sèche et les dîmes de leurs vignes de Saint-Bris. Geoffroy a offert ces dons sur l'autel de l'église de Reigny. Voir en annexe, le tableau récapitulant les motifs des actions juridiques.

57. Alexandra GAJEWSKI, «Burial, cult, and construction at the abbey church of Clairvaux (Clairvaux III) ", dans Sepulturae cistercienses. Sépulture, Mémoire et patronage dans les monastères cisterciens au Moyen Âge, Cîteaux, t. 56, 2005, fasc. 1-4, p. 47-85, p. $56-57:$ «... the first statute relating to burial in churches... is dated in two manuscripts to 1180 . It specified that no-one should be buried in the church with the exception of bishops, archbishops, kings, and queens ».

58. François BOUGARD, «Conclusion », dans Sauver son âme et se perpétuer, Rome, 2005, [note 55], p. 494. Stephen WEINBERGER, « Donations-ventes ou ventes-donations? Confusion ou système dans la Provence du XI ${ }^{\mathrm{e}}$ siècle », Le Moyen Âge, 105, 1999, p. 667-680.

59. AD Yonne, H 1565 : Jocelinus de Avalone dedit et concessit, pro salute anime sue et antecessorum suorum, Deo et beate Marie et fratribus de Regniaco omnes pasturas terre sue, tam plane quam nemorose, que sita est in omni finagio de Arsi, citra Coram fluvium et ultra, sine dampno segetum, pratorum et vinearum, jure perpetuo possidendas.

60. Porro vero dictus Jocelinus, hujus rei causa, habuit, de beneficio domus Regniaci, ducentas oves et unum equum.

61. AD Yonne, H 1627 : Gibaudus de sancto Verano, et frater ejus Rainaldus, concesserunt et laudaverunt, per manum Radulphi, venerabilis abbatis de Fonteneto, presente Theobaldo, abbate de Scarliis, et Willelmo, ejusdem loci quondam abbate, tunc monacho Fonteneti, et Gaufrido de Monte-Regali, et Rainaldo de Ratille, militibus, Deo et beate Marie de Regniaco, et Ascelino, abbati ejusdem loci et fratribus ejus in perpetuum, quicquid fratres illi acquisierant in terra de Toire, sive proprium in manu eorum, sive de casamento eorum esset, perceptis per hoc quingentis solidis et equo uno.

62. AD Yonne, H 1566 : dominus Reinerius de Castelluz dedit Deo et Beatce-Marice de Reigniaco et fratribus ejusdem loci, pro anima sua et uxoris suce Agnetis, et pro animabus antecessorum suorum, libere et perpetuo possidendum et absque ulla retentione, quicquid habebat in finagio de Triclin, citra aquam, videlicet in nemoribus, in pratis, terris vel in aquis: quce omnia de capite suo movebant. Et propter ista fratres de Reigniaco dederunt ei ducentos agnos et unum palefridum.

63. AD Yonne, H 1562-2. Voir le texte mis en annexe.

64. Concernant le patrimoine, ce sujet ne m'intéresse pas ici. Reigny est une abbaye riche à la fin du XII ${ }^{\mathrm{e}}$ siècle, à la tête de nombreuses granges bien gérées et bien défendues, mais ceci est une autre histoire. 
65. Benoît CHAUVIN, Vauxbons, abbaye cistercienne au diocèse de Langres (... 1175 - 1394...). Etude historique et édition du chartrier, L'Hermitage, 2005, p. 38. Chrysogonus WADDELL, Narrative and legislative texts from early Cîteaux, Cîteaux, 1999, Capitula, XXIII, p. 191 et Instituta generalis capituli, IX, p. 328 : Ecclesia, altaria, sepulturas, decimas alieni laboris vel nutrimenti, villas, villanos, terrarum census, furnorum et molendinorum redditus, et cetera his similia monastice puritati adversantia, nostri et nominis et ordinis excludit institutio.

66. Deux mots en partie effacés.

67. $A^{2}$ n'est pas daté et toute sa partie gauche est rongée par l'humidité.

INDEX

Mots-clés : abbaye cistercienne

Index géographique : France/Reigny 